\title{
PERFORMANCE OF SISAL FIBER IN MANUALLY CRUSHED PALM KERNEL SHELL CONCRETE
}

\author{
Ishaya, A. A., Anowai, S. I., Yahaya, A. M., Williams, F. N. \& Emeka, O. B. \\ Department of Building, University of Jos, Jos Nigeria \\ E-mail: $\underline{\text { aawari@yahoo.com }}$
}

DOI: 10.31364/SCIRJ/v7.i5.2019.P0519651

http://dx.doi.org/10.31364/SCIRJ/v7.i5.2019.P0519651

\begin{abstract}
One of the major challenges of our present society is the protection of the environment. Some of the important elements in this respect are the reduction of the consumption of energy, natural raw materials and the utilisation of waste materials. The used of waste is showing prospective application in construction as alternative to conventional materials. It conserves natural resources and reduces the space required for the landfill disposal. Palm kernel shell is a byproduct of the production of palm oil. Previous works indicate that palm kernel shell performs satisfactorily as an aggregate for lightweight concrete. This research therefore was carried out in an attempt to evaluate the performance of sisal fiber in palm kernel shell concrete. The palm kernel shell used for this research was determined to have a specific gravity of 1.36, bulk density of $574 \mathrm{~kg} / \mathrm{m3}$ and was therefore classified as lightweight aggregate. Values of water absorption and porosity of the shell were found to be $11.43 \%$ and $14.70 \%$ respectively. A mix proportion of 1:2:4 and water - cement ratio of 0.63 was adopted for all the concrete mixes. A total 36 concrete cubes of size $150 \mathrm{~mm} \times 150 \mathrm{~mm} \times 150 \mathrm{~mm}$ were cast with $1 \%, 2 \%$ and $3 \%$ sisal fiber and were crushed to obtain the compressive strength at 7, 14 and 28 days of curing, 12 concrete beams were also produced and tested for flexural strength. An increase in compressive strength by $51.2 \%$ was observed at $3 \%$. It was concluded that $3 \%$ sisal fiber can be adopted for lightweight concrete work.
\end{abstract}

Keywords: Compressive strength, palm kernel, lightweight concrete, water cement ratio, water absorption

\section{INTRODUCTION}

Concrete is one of the most widely used construction material in the world. Its great versatility and relative economy in filling wide range of needs has made it a competitive building material (Sashidar and Rao, 2010). Concrete production is not only a valuable source of societal development, but it is also a significant source of employment (Naik, 2008). Production of concrete relies to a large extent on the availability of cement, sand and coarse aggregates such as granite, the costs of which have risen astronomically over the past few years. Despite the rising cost of production, the demand for concrete is increasing. The negative consequences of the increasing demand for concrete include depletion of aggregate deposits; environmental degradation and ecological imbalance. The possibility of complete depletion of aggregates resources in the near future can therefore not be over emphasized. Rising construction costs and the need to reduce environmental stresses to make construction sustainable, has necessitated research into the use of alternative materials, especially locally available ones which can replace conventional ones used in concrete production. The use of such re-placement materials should not only contribute to construction cost reduction and drive infrastructural development but also contribute to reduce stress on the environment and make engineering construction sustainable to help transform the building and construction sectors of national economies and contribute towards the realization of 
national and global poverty reduction strategies. Such materials should be cheap and readily available. The use of cheaper building materials without loss of performance is very crucial to the growth of developing countries.

Historically, agricultural and industrial wastes have created waste management and pollution problems. However the use of agricultural and industrial wastes to complement other traditional materials in construction provides both practical and economical advantages. The wastes generally have no commercial value and being locally available, transportation cost is minimal (Chandra and Berntsson, 2002). Agricultural wastes have advantages over conventional materials in low cost construction (Abdullah , 1997). The use of waste materials in construction contribute to conservation of natural resources and the protection of the environment.

Boban Nair, Shiji and Cherian (2017) presented an experimental method for incorporating water hyacinth fibre in concrete. Water hyacinth was used as partial replacement for fine aggregate at $0.5 \%, 1 \%, 1.5 \%$ and $2 \%$ by weight. Test results revealed that concrete cubes with $0.5 \%$ water hyacinth fiber substitution for the aggregate produced comparatively high compressive strength values. It was also observed that the use of water hyacinth fiber in concrete has reduced water absorption characteristics, enhanced durability and improved compressive strength at higher temperature

The palm oil industry produces wastes such as palm kernel shells, palm oil fibers which have been used as fuelling material at home and for industries or dumped in the open, thereby impacting the environment negatively without any economic benefits. Palm kernel shells (pks) are hard, carbonaceous, organic byproducts of the processing of the palm oil fruit. Pks consists of small size particles, medium size particles and large size particles in the range 0-5mm, 5-10mm and 10-15mm (Alengaram, Mahmud, Jumaat and Shiraz, 2010). The shells have no commercial value, but create disposal and waste management problems. In Ghana, palm kernel shells are generally not used in construction. They are used as fuel by local blacksmiths and as fill material or as palliatives. Ndoke (2006) investigated the suitability of palm kernel shells as partial replacement for coarse aggregates in asphaltic concrete. Olutoge (2010) investigated the suitability of sawdust and palm kernel shells as replacement for fine and coarse aggregate in the production of reinforced concrete slabs. He concluded that $25 \%$ sawdust and palm kernel substitution reduced the cost of concrete production by $7.45 \%$. He also indicated the possibility of partially replacing sand and granite with sawdust and palm kernel shell in the production of lightweight concrete slabs. Olanipekun (2006) compared concrete made with coconut shells and palm kernel shells as replacement for coarse aggregates and concluded that coconut shells performed better than palm kernel shells as replacement for conventional aggregates in the production of concrete. Oil Palm trees grow in the coastal belt in Nigeria which varies in depth from 100 to 150 miles and a riverine belt which follows the valleys of the Niger and Benue for a distance of about 450 miles from the sea. The main palm oil producing states in Nigeria include Ogun, Ondo, Oyo, Edo, Cross River, Anambra, Enugu, Ebonyi Imo, Abia, Ekiti, Akwa-Ibom, Delta and Rivers

The use of fibers as reinforcement is as old as human civilization. Traces of natural fibers such as flax, cotton, silk, wool and plant fibers have been located in ancient civilizations all over the globe. For example, the recorded usage of flax can be dated back to 
$5000 \mathrm{BC}$; it is considered the oldest natural textile fiber. More recently, the use of natural fibers in construction has been limited to thin elements for roofing, cladding, internal and external partitioning walls; these have been produced in an effort to develop low cost materials and as a substitute for asbestos. These cement composites were mainly reinforced by short or pulp cellulose fibers. Natural plant fibers are renewable resource, eco-friendly, economical and are available in most developing countries and requires only a low degree of industrialisation for their processing and in comparison with equivalent weight of the most common synthetic reinforcing fibers (Vajje and Krishna murphy, 2013).

Given the resurgent interest in building with palm kernel shell, this research studies the properties of manually crushed palm kernel shell and the performance of sisal fiber in palm kernel shell concrete in terms of compressive strength, flexural and water absorption. Basically the research is meant to investigate the strength of palm kernel shell concrete with various percentage of sisal fiber in order to ascertain the appropriate percentage sisal fiber that will be suitable for the production of palm kernel shell concrete

\section{STATEMENT OF PROBLEM}

Apart from the high cost of concrete, natural resources is decreasing on daily basis worldwide, and the use of available local material is low at the same time the waste generated from palm kernel shell is increasing substantially, these waste when not utilized lead to increase in problem of waste management. The problem of disposing and managing solid waste materials in all countries has become one of the major environmental, economical, and social issues. A complete waste management system including source reduction, reuse, recycling, land-filling, and incineration needs to be implemented to control the increasing waste disposal problems,

The sustainable development for construction involve the use of non- conventional and innovative materials and recycling of waste materials in order to compensate the lack of natural resources and to find alternative ways for conserving the environment.

\section{AIM AND OBJECTIVES}

The aim of this research is to examine the performance of sisal fiber in manually crushed palm kernel shell concrete and address the following objectives:

I. To determine the compressive and flexural strength of manually crushed palm kernel shell concrete reinforced with sisal fiber

II. To determine the density and water absorption of manually crushed palm kernel shell concrete reinforced with sisal fiber

III. To determine the workability of manually crushed palm kernel shell concrete reinforced with sisal fiber

\section{MATERIALS AND METHODS}




\section{Materials}

Dangote ordinary Portland cement (ASTM Type 1) manufactured by Benue cement company obtained from local suppliers in Jos, Plateau State, Nigeria and was used as binder, sand as fine aggregate, palm kernel shell as coarse aggregate, sisal fiber and tap water. The palm kernel shell used for this research was obtained from Achara in Nsukka local government area of Enugu State. It was obtained after extracting the oil and was kept indoors in sacks. The shell was washed in order to remove unwanted material - particularly traces of oil. Testing of aggregates was done as per relevant BS or ASTM.

\section{Mix proportion}

The mix used for all the concrete cubes cast and beams in this work was 1:2:4 and with a constant free water - cement ratio (w/c) ratio of 0.63. The respective Absolute Volumes (AV) of the materials were calculated using the following equation.

Absolute Volume $(\mathrm{AV})=$ Mass ratio $\mathrm{x}$ Density/ specific gravity

The calculated Absolute Volumes are: Palm kernel shell aggregates $\left(0.02025 \mathrm{~m}^{3}\right)$, cement $\left(0.005060 \mathrm{~m}^{3}\right)$, sand $\left(0.01013 \mathrm{~m}^{3}\right)$ and water. While the corresponding Absolute Volumes for concrete beams were cement $\left(0.00225 \mathrm{~m}^{3}\right)$, sand $\left(0.00450 \mathrm{~m}^{3}\right)$ and palm kernel shell $\left(0.0090 \mathrm{~m}^{3}\right)$

Quantities of materials $(\mathrm{kg})$ per $\mathrm{m}^{3}$

The mass of materials are calculated using the following relation.

Mass of material $=$ Mix ratio $\mathrm{x}$ Density/Total AV

Mass determined : Palm kernel shell (27.54kg), Cement (15,94kg), Sand (26.84kg) and Water (10.04kg). Beams, Cement $(7.09 \mathrm{~kg})$, Sand $(11.92 \mathrm{~kg})$ and Palm kernel shell $(12.24 \mathrm{~kg})$.

\section{Test methods}

The compressive strength of standard cubes $150 \mathrm{mmx} 150 \mathrm{mmx} 150 \mathrm{~mm}$ metallic mould and (100mm diameter $\mathrm{x} 200 \mathrm{~mm})$ were determined as per BS 1881: part 116 and part 110 respectively. Beams of size 100mmx100mmx500mm for flexural test (ASTM C78-02) was employed. Tests for compressive strength were carried out at percentages replacement of $1 \%, 2 \%, 3 \%$ of sisal fiber cured for periods of 7, 14 and 28 days whereas for flexural strength at 28 days. For all tests each result was the average of three samples. 


\section{RESULTS AND DISCUSSION}

\section{Slump and compacting factor values}

Table 1 shows the water - cement ratio, slump and compacting factor values for the mix. It was observed that the compacting factor values range between 0.66 and 0.71 . The slump values on the other hand ranged between $7.2 \mathrm{~mm}$ and $8.9 \mathrm{~mm}$. This therefore indicates a range of workability between low and medium (BS 1881 part 103: 1993). The mix was dry due to the water absorbing nature of the fiber which made compacting difficult.

\section{Water Absorption}

The water absorption of the palm kernel shell was found to be $11.43 \%$ which can be compared with $14.02 \%$ obtained by (Umoh and Ekop, 2013). The water absorption capacity of the shell was rather too high. This is attributed to the porous nature of the shells. The implication of this is that if concrete is produced using this aggregate without making allowance for more water to be added in the mix, workability would be impaired. In other words, it would decrease workability. Table 2 also shows the relationship between water absorption of the cubes and the various percentage of addition of sisal fiber. The results shows values between $0.52 \%$ and $1.04 \%$ which is consistent with the findings of Neville (2011) that water absorption of good concrete falls below $10 \%$.

\section{Density of concrete cubes}

It was observed that the density in Table 3 was affected by the hydration period for the mixes. The density increases progressively with increase in hydration period. This could be attributed to the hydration product which occupies the space and occupied by the cement and some interstitial spaces originally filled with water. This consequently reduces available pore spaces with consequent increase in density.

Neville (2011) gives the range of densities of lightweight concrete as being between 300 and

$1850 \mathrm{~kg} / \mathrm{m}^{3}$. The densities obtained in this research ranged between 1505 and $2014 \mathrm{Kg} / \mathrm{m}^{3}$, thus enabling the concrete so made to be classified as lightweight aggregate concrete.

\section{Compressive strength of palm kernel shell sisal fiber concrete}

The result of the development of compressive strength with hydration period of 7, 14 and 28 days are given in Table 4 .

The results show that at constant water-cement ratio of 0.63 , compressive strength continued to increase with age. Fig 1 also shows that the rate of increase in compressive strength over time was more or less linear. The rate of increase of strength however decrease slightly with increase in hydration period. For $2 \%$ sisal fiber the ratios of 14 to 7 days, 28 to 14 days were 1.04 and 1.03 respectively, while for 1 and $3 \%$ sisal fiber, the ratios of 14 to 7 days, 28 to 14 days were 1.08 and $1.09,1.01$ and 1.03 respectively as shown in Table 5 . 
The continual increase in strength as hydration progressed and at decreasing rate for $2 \%$ sisal fiber, indicates that no noticeable deterioration of the concrete has occurred with the 28-day curing period. The palm kernel shell being inert and an organic material may therefore be concluded to be vulnerable only to strongly acidic or alkaline solutions. However, if any reaction were to have occurred, it would have done so before hardening of the concrete. This means that were any reactions to have been noticed, it would have been during the early stages. But this was not the case. The British standard recommends a compressive strength of at least $15 \mathrm{~N} / \mathrm{mm}^{2}$ measured on a cube for structural lightweight concrete. Considering the $15.62 \mathrm{~N} / \mathrm{mm}{ }^{2}, 16.88 \mathrm{~N} / \mathrm{mm} 2$ and $18.07 \mathrm{~N} / \mathrm{mm}^{2}$ respectively and corresponding to the $1 \%, 2 \%$ and $3 \%$ sisal fiber with a constant w/c of 0.63 can be used as a structural lightweight aggregate concrete. This also met the requirement of lightweight concrete as stated by (Reynolds and Steedman, 2001) and falls within the range of 5 to $28 \mathrm{~N} / \mathrm{mm}^{2}$ of palm kernel shell concrete with mix ratio of 1:2:4 as reported by (Okafor 1998)

\section{Flexural Strength}

The results in Table 6 shows the flexural strength of palm kernel shell sisal fiber concrete at 28 days hydration period. The 28 - day flexural strength of pks sisal fiber concrete at 1\%, $2 \%$ and $3 \%$ addition of sisal fiber is approximately $14 \%$ of its compressive strength, this met the requirement of lightweight concrete beam in BS 881, part 1, 1997. These value can also be compare to $2.53 \mathrm{~N} / \mathrm{mm}^{2}$ to $2.81 \mathrm{~N} / \mathrm{mm}^{2}$ obtain by Okpala 1990 and is also in accordance with BS 8110: 1997

The relation between the flexural and compressive strength for NWC depends on the type and properties of coarse aggregate used (Neville, 2011). The flexural strength of NWC ranges between $11 \%$ and $23 \%$ of the compressive strength

Table 1: Workability of Palm Kernel Shell Sisal Fiber Concrete

\begin{tabular}{ccccc}
\hline \%Sisal fibre & $\begin{array}{c}\text { Length of fibre } \\
(\mathbf{m m})\end{array}$ & W/C & Slump(mm) & $\begin{array}{c}\text { Compacting } \\
\text { factor }\end{array}$ \\
\hline 0 & 50 & 0.63 & 8.9 & 0.71 \\
1 & 50 & 0.63 & 7.5 & 0.66 \\
2 & 50 & 0.63 & 7.8 & 0.70 \\
3 & 50 & 0.63 & 7.2 & 0.68 \\
\hline
\end{tabular}

Table 2: Water Absorption for Palm Kernel Shell Sisal Fiber Concrete at 28 days

\begin{tabular}{ccc}
\hline$\%$ Sisal fiber & $\begin{array}{c}\text { Length of fiber } \\
(\mathbf{m m})\end{array}$ & $\begin{array}{l}\text { Water } \\
\text { absorption \% }\end{array}$ \\
\hline 0 & 50 & 0.52 \\
1 & 50 & 1.03 \\
2 & 50 & 0.95 \\
3 & 50 & 1.04 \\
\hline
\end{tabular}

Table 3: Density of palm kernel shell sisal fibre concrete

\begin{tabular}{cc}
\hline \% Sisal fiber & Density $\left(\mathbf{K g} / \mathbf{m}^{\mathbf{3}}\right)$ \\
\hline C) 2019, Scientific Research Journal & $\stackrel{\text { wwW.scirj.org }}{\text { http://dx.doi.org/10.31364/SCIRJ/v7.i5.2019.P0519651 }}$
\end{tabular}




\begin{tabular}{rrrr} 
& \multicolumn{1}{c}{ 7 days } & 14days & 28 days \\
\hline 0 & 1487 & 1645 & 1700 \\
1 & 1505 & 1660 & 1671 \\
2 & 1730 & 1833 & 1848 \\
3 & 1939 & 2014 & 2002 \\
\hline
\end{tabular}

Table 4: Compressive strength of palm kernel shell sisal fiber concrete

\begin{tabular}{ccccc}
\hline \% Sisal fiber & $\begin{array}{c}\text { length of } \\
\text { fiber }(\mathbf{m m})\end{array}$ & \multicolumn{3}{c}{ Compressive strength $\left(\mathbf{N} / \mathbf{m}^{\mathbf{2}}\right)$} \\
\cline { 3 - 5 } & 50 & $\mathbf{7}$ days & $\mathbf{1 4}$ days & $\mathbf{2 8 \text { days }}$ \\
\cline { 3 - 5 } 0 & 50 & 9.04 & 11.04 & 11.95 \\
1 & 50 & 13.19 & 14.29 & 15.62 \\
2 & 50 & 15.77 & 16.44 & 16.88 \\
3 & 17.25 & 17.50 & 18.07 \\
\hline
\end{tabular}

Table 5: Ratios of 14 - day, 28 - day Strength to 7 - day Strength for Palm Kernel shell Sisal Fiber Concrete

\begin{tabular}{cccc}
\hline \% Sisal fiber & W/C ratio & $\begin{array}{c}\text { 14 days to } \\
\text { days strength }\end{array}$ & $\begin{array}{l}\text { 28days to 14 } \\
\text { day strength }\end{array}$ \\
\hline 0 & 0.63 & 1.22 & 1.08 \\
1 & 0.63 & 1.08 & 1.09 \\
2 & 0.63 & 1.04 & 1.03 \\
3 & 0.63 & 1.01 & 1.03 \\
\hline
\end{tabular}

Table 6: Flexural strength for palm kernel sisal fibre concrete at 28 days

\begin{tabular}{cccc}
\hline \% Sisal fibre & Length of fibre & Density $\mathbf{K g} / \mathbf{n}^{\mathbf{2}}$ & $\begin{array}{c}\text { Flexural } \\
\text { strength }\end{array}$ \\
\hline 0 & 50 & 1554 & 2.00 \\
1 & 50 & 1601 & 2.12 \\
2 & 50 & 1637 & 2.43 \\
3 & 50 & 1710 & 2.60 \\
\hline
\end{tabular}




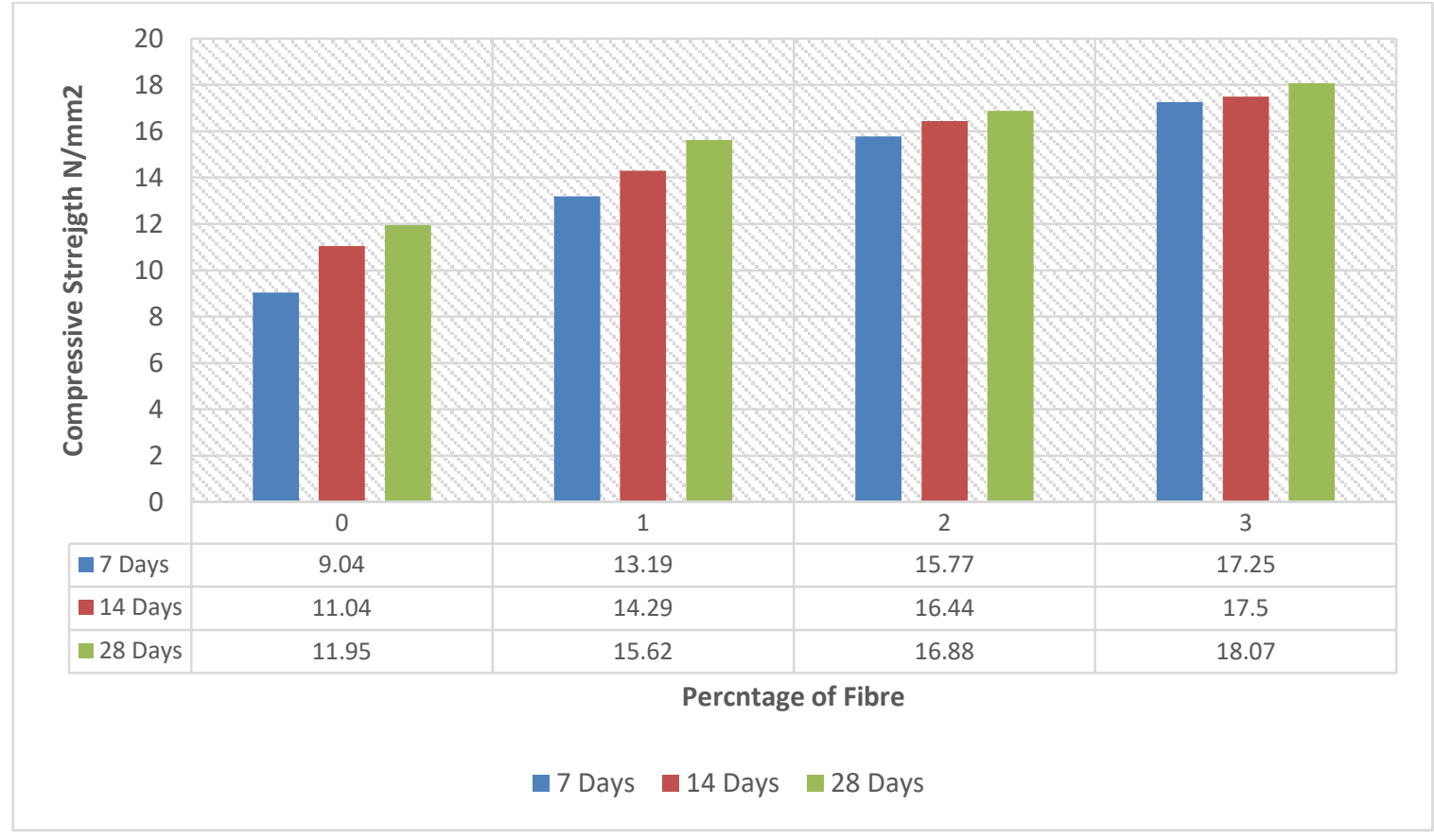

Fig 1: Bar chart showing comparison of compressive strength at 7, 14 and 28 days curing

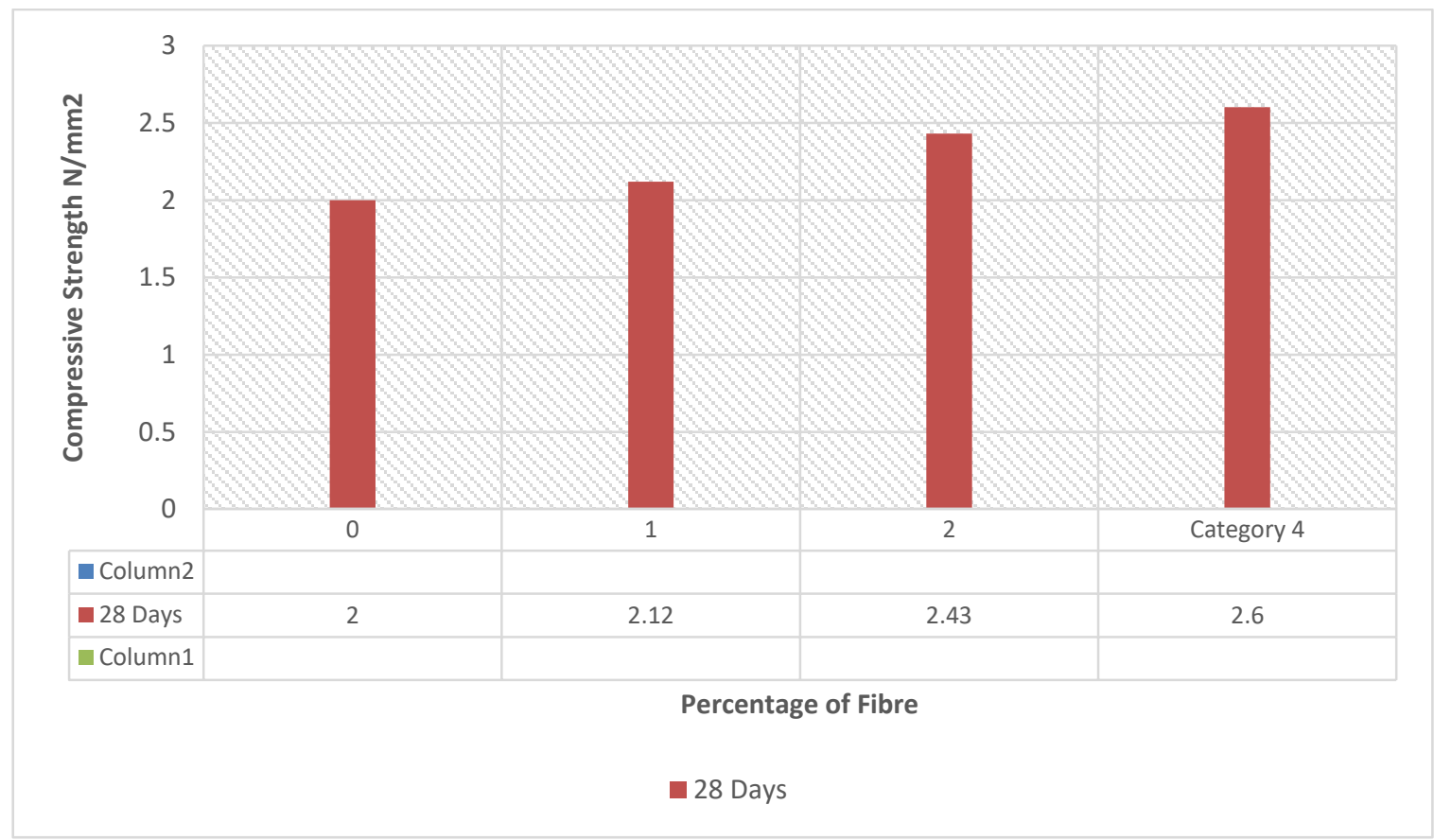

Fig 2 : Bar chart showing flexural strength cured at 28 days

\section{CONCLUSIONS}

1. The palm kernel shell used in this research work has a maximum size of $10 \mathrm{~mm}$ which agrees with $0.5 \mathrm{~mm}, 5 \mathrm{~mm}$ to $10 \mathrm{~mm}$ and $10 \mathrm{~mm}$ to $15 \mathrm{~mm}$ ( Alengaram, Mahmud, Jumaat and Shiraz 2010). 
2 The palm kernel shell used in this research work has specific gravity of 1.36 which

can be compared to 1.58 obtained by

Olusola and Babafemi (2013) and 1.37 obtained by Umoh (2013).

3 The palm kernel shell used in this research work has a compacted and uncompacted densities of $574 \mathrm{~kg} / \mathrm{m}^{3}$ and $500 \mathrm{~kg} / \mathrm{m}^{3}$ respectively, which conform with lightweight aggregate as specified by Neville (2011) which is between $300 \mathrm{~kg} / \mathrm{m}^{3}$ to 1100 $\mathrm{kg} / \mathrm{m}^{3}$

4 The palm kernel shell water absorption capacity and porosity were $11.43 \%$ and $14.79 \%$ respectively which indicate higher water absorption and porosity of light weight aggregate. Water absorption of the manually crushed palm kernel shell falls within the range of $5-20 \%$ water absorption for lightweight aggregate.

5 The sand use for this research work met the requirement recommended in

\section{BS 882:1992}

6 Workability decreases with increase in percentage of sisal fiber, therefore this indicates a range of workability between low and medium as in BS 1881: part 1031993.

7 From the results obtained for 7, 14, and 28 days curing regime in Table 4, it was observed that the 28 - day compressive strength of manually crushed palm kernel shell sisal fiber concrete ranges between $15.62 \mathrm{~N} / \mathrm{mm}^{2}$ and $18.07 \mathrm{~N} / \mathrm{mm}^{2}$

8 The 28 - day flexural strength of palm kernel shell sisal fiber concrete is between $2.12 \mathrm{~N} / \mathrm{mm}^{2}$ and $2.6 \mathrm{~N} / \mathrm{mm}^{2}$ averaging $14 \%$ of its compressive strength, this met the requirement of lightweight concrete beam in BS 881, part 1, 1997. These values can also be compared to $2.53 \mathrm{~N} / \mathrm{mm} 2$ and $2.81 \mathrm{~N} / \mathrm{mm}^{2}$ obtained by Okpala, 1990 and in accordance with BS 8110 : 1997.

Therefore, from the results of the investigations, it is thus recommended that sisal fiber can be use to reinforce manually crushed palm kernel shell concrete up to $3 \%$ for specific light weight concrete construction work, while $2 \%$ optimum value was recorded for flexural strength

\section{REFERENCES}

Abdullah A. A. A. (1997). Palm Oil Shell as Aggregate for Lightweight Concrete. In S. Chandra (Ed) Waste Materials Use in Concrete Manufacturing, New York: Noyes Publications)

Alengaram U. J. H., Mahmud, M. Z., Jumaat \& Shiraz, S. M. (2010). Effect of aggregate size and proportion on strength properties of palm kernel shell concrete. International Journal of the Physical Sciences, 5 (12), 1848-1856

ASTM (1978). American Standard for Testing Materials. ASTM C330-77. Specification for light weight aggregate for structural concrete. 
Babafemi \& Olusola, (2013): Influence of curing media on the compressive strength of palm kernel shell (PKS) concrete. Unpublished undergraduate project, Department of Building, Obafemi Awolowo University, Ile-Ife, Nigeria.

British Standard Institution (1997). BS 8110-Part 1. The Structural Use of Concrete, BSI. London

British Standard Institution. (1993). BS 1881-Part 108 Method for Making Test Cubes from Fresh Concrete. BSI. London.

British Standard Institution. (1983). BS 1881- Part 103 Method for Determination of Compacting Factor, BSI. London.

Chandra, S. \& Berntsson, L. (2002). Lightweight Aggregate Con-crete Science Technology and Applicaton. Noyes Publication. New York.

Vajje, S., \& Krishna murthy, N. R. (2013). Study on addition of the natural fibres into Scientific \& Technology Research, 2(11), $213-218$

concrete. International Journal of

Neville, Adam M (2011). properties of Concrete A.M.Neville- $5^{\text {th }}$ ed. p.cm.

Ndoke, P. N. (2006), Performance of palm kernel shells as a partial replacement for coarse aggregate in asphalt concrete. Leonardo Electronic J Practices And Technologies,5(6),145-152

Naik, T. R. (2008). Sustainability of Concrete Construction. Practice Periodical on Structural Design And Construction.13(2), 98103.

Okpala, D. C. (1990): Palm Kernel Shell as a lightweight aggregate in concrete. London: Building and Environment 25(4), 291 296.

Okafor, F. O. (1998). Palm Kernel Shell as a lightweight aggregate for concrete, cement and concrete research 18, accessed online on $30^{\text {th }}$ April, 2012, pp. $901-910$.

Olutoge, F .A. (2010), “ A study of Sawdust, Palm Kernel Shell and Rice Husk Ash as Full/Partial Replacement for sand, Granite and Cement in concrete", Unpublished M.Sc. Thesis, Department of Building, University of Lagos, Nigeria,

Olanipekun E. A., Oluola, K. O. \& Ata, O. (2006). "A comparative study of concrete properties using coconut shell and palm kernel shell as coarse aggregates", Building and Environment, Vol. 41, pp. 297-301.

Reynolds, E. C. \& Steedman, C. J. (2001). Reinforced Concrete Designer's Handbook Published by E \& FN Spon, 10Ed. Taylor \& Francis Group New Fetter Lane London

Umoh, E. (2013): Use of Erosion sand and Palm Kernel Shell as aggregates in the production of structural lightweight concrete. Unpublished B.Sc. project, University of Uyo production. 